\title{
Endophytic seed mycobiome of six sorghum (Sorghum bicolor) cultivars from commercial seedlots using an Illumina sequencing approach
}

\author{
Kinge $\mathrm{TR}^{1,2}$, Cason $\mathbf{E D}^{3}$, Valverde $\mathrm{A}^{3}$, Nyaga $\mathbf{M}^{4}$ and Gryzenhout $\mathbf{M}^{1}$ \\ ${ }^{1}$ Department of Genetics, University of the Free State, Bloemfontein, P. O. Box 339, Bloemfontein, Republic of South \\ Africa \\ ${ }^{2}$ Department of Biological Sciences, Faculty of Science, The University of Bamenda, P.O. Box 39, Bambili, North West \\ Region, Cameroon \\ ${ }^{3}$ Department of Microbial, Biochemical and Food Biotechnology, University of the Free State, Bloemfontein, Republic \\ of South Africa \\ ${ }^{4}$ Next Generation Sequencing Unit, Department of Medical Virology, Faculty of Health Sciences, University of the \\ Free State, Bloemfontein, South Africa, University of the Free State, Bloemfontein, Republic of South Africa
}

Kinge TR, Cason ED, Valverde A, Nyaga M, Gryzenhout M 2019 - Endophytic seed mycobiome of six sorghum (Sorghum bicolor) cultivars from commercial seedlots using an Illumina sequencing approach. Mycosphere 10(1), 739-756, Doi 10.5943/mycosphere/10/1/16

\begin{abstract}
Pathogen-free seeds are important for the establishment of young seedlings, prevention of health problems upon consumption by animals and livestock, and inadvertent movement of pathogens into and out of countries. However, testing for the presence of fungi, including pathogens from seeds is a time consuming and difficult process. In this study, we characterized the seed fungal microbiome (mycobiome) of six commercial sorghum cultivars from South Africa using a deep amplicon next generation sequencing approach based on the Internal Transcribed Spacer (ITS) region of the ribosomal operon. Sorghum is the fifth most important crop in the world, and widely used by African farmers. We found that the fungi present in each of the seedlots were similar to those reported by cultural studies. By comparing phylotypes of certain key families and genera to phylotypes used in established phylogenies and reputed sequences from public databases, the diagnostic value of the NGS method was also investigated. We showed that a number of molecular operational taxonomic units (MOTUs) could be identified at the species level and established that certain known pathogens are not present in the tested seeds, for instance in the Aspergillus group. Other groups could not be identified, not even to genus level. While acknowledging the shortcomings of using partial ITS data, we demonstrated that deep amplicon sequencing is a valuable diagnostic tool for seed disease control and prevention in some cases.
\end{abstract}

Key words - Deep amplicon sequencing - Diagnostics - Endophytic Fungi - Pathogens - Seedborne fungi

\section{Introduction}

Pathogen-free seeds are one of the most important factors for successful crop production. Many plant pathogens are seed-borne and can cause failed establishment of plants, enormous crop losses, the reduction in plant growth and productivity, and high costs to eradicate the pathogens once established (Dawson \& Bateman 2001, Islam et al. 2009). For instance, when untreated seeds 
are grown in the field, seed-borne pathogens of sorghum are responsible for variation in plant morphology and yield reduction of up to $90 \%$ (Wiese 1984). Seed-borne pathogens also cause spoilage when seeds are used as food, or contamination of grain through the productions of toxins that can negatively affect humans and livestock that consume the seeds (González et al. 2008).

The seed microbiome consists of obligate and facultative endophytes (ubiquitous microbes occurring inside living plant tissues that do not cause any apparent symptoms in the plant) inside the seed, and those organisms occurring on the exterior (Baldani et al. 1997, Ferreira et al. 2008, Kaga et al. 2009). Vertically-transmitted endophytes represent the seed core microbiome, usually occurring in seeds over many generations (Hodgson et al. 2014). Horizontally-transmitted microorganisms from the environment constitute the accessory microbiome (Hodgson et al. 2014). Endophytes can be mutualistic symbionts that, for instance, enhance growth, and confer tolerance to abiotic stress, or resistance to pests, herbivores and pathogens (Hyde \& Soytong 2008, Oldrup et al. 2010, Ralphs et al. 2011, Cook et al. 2013, Wani et al. 2015). Phytopathogenic and rotting organisms can also have latent endophytic phases, but these do not always have vertical transmission, as in the case of members of the genera Alternaria and Cladosporium (Oliver et al. 2001, Galperin et al. 2003, Sowley et al. 2010). The majority of pathogenic fungi in seeds are probably derived from the environment such as surrounding soil and air in either the field or storage places, when fungal propagules land on the exterior of the seed coat before germination (Hodgson et al. 2014, Parsa et al. 2016).

Sorghum (Sorghum bicolor) is the fifth most important grain crop in the world after wheat, maize, rice and barley. In semi-arid regions of Africa, Asia and Latin America, it is one of the major staple food crops (Rooney \& Waniska 2004, Dicko et al. 2006), especially in many rural communities. This is especially true in the more drought prone areas of South Africa where this hardy crop provides better household food security than maize (Patil et al. 2014). Seventeen of the twenty-five species of sorghum are native to Australia, with the range of some extending to Africa, Asia, Mesoamerica, and certain islands in the Indian and Pacific oceans (Spenceley et al. 2005). Sorghum bicolor is native to Ethiopia (Adugna 2014) while other species of sorghum native to Africa include Sorghum arundinaceum, Sorghum drummondii and Sorghum halapensis (Royal Botanic Gardens Kew \& Missouri Botanic Garden 2017).

Despite the economic importance of sorghum, only a limited number of studies have focused on diseases and food problems linked to sorghum seeds, and mainly on grain mold disease, which is caused by different fungi in the genera Fusarium, Alternaria, Cochliobolus and Cladosporium (Frederiksen \& Odvody 2000, Tarekegn et al. 2006, Sharma et al. 2010). Seed-borne pathogens can be responsible for deteriorating seed quality during storage and can be viable even after seeds have been treated with fungicides. Reported species include Alternaria alternata, A. tenuissima, A. longissimi, Fusarium culmorum, $F$. moniliforme, the $F$. incarnatum-equiseti species complex, $F$. andyazi, $F$. thapsinum, the $F$. oxysporum species complex and the $F$. chlamydosporum species complexes, Curvularia penniseti, C. lunata, Drechslera rostrata, Exserohilum rostratum Aspergillus fumigatus, A. niger, A. flavus, Phoma spp., Epicoccum sorghinum, Gonatobotrys spp., Mucor spp., Cladosporium spp. Aureobasidium pullulans, Rhizopus stolonifera, R. nigricans, and Phytophthora spp. (Kassim 1985, Thakur et al. 2003, Leslie \& Summerell 2006, Patil et al. 2008, Zida et al. 2008, Abdulsalaam \& Shenge 2011, Panchal \& Dhale 2011, Yago et al. 2011, Stokholm et al. 2016). In South Africa, the dominant fungal genera in sorghum seeds are Alternaria, Phoma, Epicoccum, Fusarium, Cladosporium and Curvularia spp. (Tesfaendrias et al. 2011, Beukes et al. 2017).

More research has been done in sorghum seeds to study contamination by mycotoxins and fungi that produce mycotoxins. Sorghum is susceptible to infection by mycotoxigenic fungi such as Aspergillus flavus, A. parasiticus (producing aflatoxins), Fusarium thapsinum (fumonisin), $F$. verticillioides and F. proliferatum (fumonisins) (Leslie \& Summerell 2006, Beukes et al. 2017). Mycotoxins are of great public health and agro-economic importance because the economic impact of mycotoxins includes loss of human and animal life, increased health and veterinary care costs, reduced livestock production, disposal of contaminated foods and feeds, and investment in research 
and applications to reduce severity of the mycotoxin problems (Zain 2011). Factors contributing to the presence or production of mycotoxins in foods or feeds include storage, environmental and ecological conditions favorable to the growth of fungi or production of toxins (Zain 2011) and are often beyond human control (Hussein \& Brasel 2001).

Traditionally, the components of the plant and seed microbiomes have been characterized by isolating and culturing microbes on different media and growth conditions. These time and effort consuming culture based techniques can miss unculturable microbial diversity, omit some species during subculturing and accurate morphological identifications require expertise (Hugenholtz et al. 1998, Jeewon \& Hyde 2007). Microbial communities are now detectable by modern culture independent techniques such as fatty acid/ protein/enzyme extractions, environmental sequencing and whole environmental metagenomes and metaproteomics (Hugenholtz et al. 1998, Mendes et al. 2011, Knief et al. 2012, Lakshmanan et al. 2014). Furthermore, environmental sequencing of communities, also named mini- or metabarcoding, or deep amplicon sequencing, gives a level of identification for the components of the communities (Li et al. 2019). Understanding community structure, dominance and latent occurrence of microbial pathogens in seeds improves epidemiological studies and strategies for disease management (Peay et al. 2016). Diagnosis of microbiomes in seeds can avoid uncontrolled propagation and quarantine breaches of pathogens through long-distance exchange of such material, will prevent economic losses more efficiently, and diminish unnecessary use of fungicides (Mancini et al. 2016). Pre-knowledge of the infection levels of potential mycotoxin-producing fungi in seeds can prevent risks associated with consumption of such contaminated foods, while a rapid technique to characterize the variation in composition of seed-borne communities between different sorghum cultivars or production areas, will significantly aid breeding efforts. Therefore, the use of a high throughput method to characterize seed microbiomes is greatly advantageous when a large number of samples or collections need to be screened.

To the best of our knowledge, the seed microbiome of sorghum has not hitherto been investigated using a non-culture-based method. The objective of this study was to characterize the seed mycobiome of six commercial sorghum cultivars from specific seedlots of sorghum by means of Ilumina sequencing of the ITS2 region. Using additional phylogenetic analyses, we also assessed the diagnostic feasibility of the method.

\section{Materials \& Methods}

\section{Plant Material}

Seed samples, pre-treated with fungicides (not disclosed by the manufacturer) of six commercial cultivars of sorghum (NS5511, PAN8816, PAN8420, PAN8625, PAN8906 and PAN8706W) were obtained from the seed company Pannar (South Africa). The cultivars were chosen based on their colour and tannin level. PAN8816, PAN8420, PAN8625 and PAN8906 are cultivars of a red variety with a low tannin and high malt content, whereas PAN8706W and NS5511 have tan coloured seeds. PAN8706W has a low tannin and malt content, and NS5511 has a high tannin and malt content.

\section{Illumina sequencing}

Twenty seeds were randomly collected from a seedlot of each of the six cultivars. Seed were surface sterilized (immersion in 3\% sodium hypochlorite for $3 \mathrm{~min}$, sterile distilled $\mathrm{H}_{2} \mathrm{O}$ for $1 \mathrm{~min}$, $70 \%$ ethanol for $2 \mathrm{~min}$, rinsed with sterile distilled water for $1 \mathrm{~min}$ ), freeze dried in $50 \mathrm{ml}$ Falcon tubes, ground, bashed with 2-mm-diameter metal beads in a Qiagen Tissue Lyser II cell disrupter (Whitehead Scientific, Cape Town, South Africa) and the powder transferred to $2 \mathrm{ml}$ Eppendorf tubes for DNA extraction. DNA was extracted using the Nucleospin ${ }^{\circledR}$ Plant II mini Kit (Macherey Nagel, Germany). DNA concentrations were determined using Nanodrop LITE spectrophotometer (Thermo Scientific, USA) and diluted to 10ng/ul. 
The ITS2 region (internal transcribed spacer) of the ribosomal operon was amplified using the primers ITS3F (5'-GCATCGATGAAGAACGCAGC-3') and ITS4R (5'TCCTCCGCTTATTGATATGC-3'), with overhang Illumina adapters (Nilsson et al. 2009, Caporaso et al. 2012). These primers are universal and result in amplicons that are variable enough to efficiently distinguish between closely related species or to identify operational taxonomic units for most fungi (Op De Beeck et al. 2014). The PCR mixture consisted of $2 \mu \mathrm{L}$ template DNA (10ng/ Ml), $1.5 \mu \mathrm{L}$ ITS 3 primer $(10 \mu \mathrm{M}), 1.5 \mu \mathrm{L}$ ITS 4 primers $(10 \mu \mathrm{M}), 12.5 \mu \mathrm{L} 2 \mathrm{U}$ HiFi ReadyMix DNA Polymerase (KAPA Biosystems, Lasec, SA) and $9 \mu \mathrm{L}$ nuclease free water (total reaction volume of $25 \mu \mathrm{L}$ ). The negative control replaced DNA with PCR-grade water to evaluate the presence of contaminants. All materials used for the preparation of reactions were sterile and nuclease free. PCR was done using a G-Storm GS04822 thermal cycler (Somerton Biotechnology Centre, United Kingdom- UK) programmed for an initial denaturation at $95{ }^{\circ} \mathrm{C}$ for $3 \mathrm{~min}$, followed by 25 cycles at $98{ }^{\circ} \mathrm{C}$ for $20 \mathrm{~s}, 65^{\circ} \mathrm{C}$ for $30 \mathrm{~s}$ and $72{ }^{\circ} \mathrm{C}$ for $30 \mathrm{~s}$, with a final extension at $72{ }^{\circ} \mathrm{C}$ for 5 min. After amplification, the PCR products were visualized under UV light by $2 \%$ agarose gel electrophoresis.

The amplicons were sent for sequencing library construction and sequencing at the Next Generation Sequencing Facility at the University of the Free State, South Africa on an Illumina MiSeq platform (Sigma-Aldrich, U.S.A). The quality and quantity assessment for the PCR products were performed using a 2100 Bioanalyzer (Agilent Technologies, Inc.), using a DNA 12000 Chip. Sample quantification was performed using the Picogreen assay (Invitrogen). Finally, the amplified PCR products, after gel purification and recovery using the Agencourt AMPure XP Bead Clean-up kit (Beckman Coulter, Inc.), was normalized, pooled and denatured before being subjected to the MiSeq system for deep sequencing using paired 300 bp reads and MiSeq v3 reagents.

\section{Cluster analysis}

The quality of the ITS sequences was performed using PrinSeq-lite v0.20.4 (Schmieder \& Edwards 2011) and trimmed to obtain an average quality score of $\geq 20$ using a 5 nt window with a 3 nt step. Sequences shorter than 200 bp were filtered out and paired end reads merged using PEAR 0.9.6 (Zhang et al. 2014). Paired end reads were analysed using QIIME v. 1.9.1 as described by Caporaso et al. (2010). Chimeric sequences were identified, using usearch 6.1.544 (Edgar 2010) as the chimera detection method (Edgar 2010), and filtered out of the quality trimmed reads by using identify_chimeric_seqs.py and filter_fasta.py commands, respectively.

Molecular Operational Taxonomic Units (MOTUs) were defined at 99\% sequence identity (Nilsson et al. 2011). Taxonomic affiliations of representative MOTUs were performed with the pick_open_refernece_otus.py script using the UNITE ITS reference database (alpha version 12_11) (Kõljalg et al. 2013). Prior to the analysis, the OTU-table was normalized using normalize_table.py in QIIME with the CSS normalization option (Paulson et al. 2013). Fungal alpha diversity (i.e. Shannon diversity) was obtained with alpha_rarefaction.py. Beta-diversity, obtained with Braycurtis distances, was visualized using a Principal Coordinates Analysis (PCoA) plot in R (www.rproject.org) with the "plot_ordination" function in the "Phyloseq" package (McMurdie \& Holmes 2013). Tentative ecological guilds were assigned to prominent MOTUs that could be assigned to genera using FUNGuild (Nguyen et al. 2016) The DNA reads were deposited under the bioproject accession no. SAMN09831275, SAMN09831276, SAMN09831277, SAMN09831278, SAMN09831279, SAMN09831280.

\section{Phylogenetic analyses}

Potentially important pathogenic MOTUs were tentatively identified with the UNITE database to genus level and were further verified using phylogenetic analyses with sequences obtained from datasets of publications and the NCBI database. This was done since species and even generic identities of a number of fungal groups are inconclusive based only on ITS data, and assignment of the generic names of MOTUs may also be incorrect (Nilsson et al. 2006, 2009). 
Special attention was given to MOTUs related to grain mold of sorghum, that were dominant in analyses or that were known to be important as pathogens or mycotoxin producers in plants.

Detailed phylogenetic analyses were done for Alternaria (dataset from Woudenberg et al. 2013), Fusarium (ITS sequences were obtained from the Multilocus Sequence Type database (http://www.westerdijkinstitute.nl/fusarium/), the Didymellaceae including genera such as Phoma and Epicoccum (dataset from Chen et al. 2015), Cladosporiaceae including genera such as Cladosporium and Toxicocladosporium (dataset from Bensch et al. 2012), Colletotrichum (dataset from Damm et al. 2009 supplemented with the type sequence option of GenBank developed by Schoch et al. 2014), Cochliobolus (dataset from Manamgoda et al. 2012, Tan et al. 2014), Erysiphe, Aspergillus, Aureobasidium and Cryptococcus (using the type sequence function of GenBank). Sequences were aligned using MAFFT (Kuraku et al. 2013, Katoh et al. 2017) using the gap option and manually checked. The curated datasets were analyzed using MEGA 7 with Maximum Likelihood (ML), using the appropriate evolutionary model per dataset determined with the model function of MEGA (indicated in phylogenetic trees included in figures). A 1000 bootstrap replication was performed to determine the statistical support of branches.



Figure 1 - Rarefaction curves of seed mycobiome for six cultivars of sorghum. 


\section{Results}

\section{Illumina sequencing}

After quality checking and data filtering the read lengths ranged from 200 to $251 \mathrm{bp}$. A minimum of 27,224 to a maximum of 94,999 sequences were retained for the different seed cultivars (Table 1). After rarefying to 27,224 sequences per sample, the number of unique MOTUs (99\% similarity cut-off) across all the seed cultivars was 5,718. These sequences represented a minimum of 834 MOTUs to a maximum of 3397 MOTUs per cultivar (Table 1). Rarefaction curves showed that deeper sequencing is needed to completely resolve the fungal diversity of the samples (Fig. 1). Percentage Relative Abundance plots (Fig. 2, Table 2) showed that the phylum Ascomycota accounted for the largest (93\% average of total number of reads) fraction of the fungi in the six sorghum cultivars. At the class, order and family level, seeds were dominated by Dothideales (41 \%, Dothideomycetes), Pleosporales (26\%, Dothideomycetes) and Pleosporaceae (16\%, Dothideomycetes, Pleosporales), respectively (Table 2). A total of thirteen different genera (Table 2) were found. "Alternaria" (family Pleosporaceae, order Pleosporales) was present in all cultivars at high levels. "Phoma" and "Epicoccum" (both Dydimellaceae, Pleosporales), were also relatively high, but were assigned under incertae sedis. "Aureobasidium" (Dothioraceae, Dothideales) accounted for the largest proportion of the Dothideales but it was only present at a very high level in cultivar PAN8816, and negligible or absent in the others. The only other genera present in higher abundance than $1 \%$ were "Cladosporium" (Cladosporiaceae, Capnodiales, Dothideomycetes) and "Fusarium" (Nectriaceae, Hypocreales), with the latter only present in cultivar NS5511. The high dominance of sequences belonging to the Pleosporales was mostly due to the presence of "Alternaria", and to a lesser degree, taxa in the Didymellaceae. Most sequences affiliated to the Dothioraceae resulted from the abundance of the genus "Aureobasidium" in the cultivar PAN8816.

MOTUs assigned to "Alternaria" were shared by seeds from all cultivars (Fig. 2). Other MOTUs that were shared included what was assigned as a "Podospora" and "Leptosphaerulina" species, and 13 MOTUs that could not be named (data not shown). Two groups of unknown MOTUs were dominantly present in all six cultivars (Fig. 2). The two principal coordinates explained the variations (differences in the six cultivars), with principal component 1 and principal component 2 showing $59.2 .9 \%$ and 32.1\% of the variation, respectively. The analysis separated the six cultivars into four groups (Fig. 3). Cultivar PAN8625 and PAN8906, and PAN8420 and PAN8907W, respectively, grouped together. PAN 8816 and NS551 grouped separately. Guild analyses (Fig. 4) showed that fungi with complex ecological roles inhabited the various seeds. Within the 16 assigned groups, roles ranged from pathogens of both animals and plants, to endophytes, to saprophytes, as for the most dominant group. This can be correlated with the presence of prominent genera such as Alternaria and Aureobasidium (Fig. 2) that have complex ecologies. Whereas endophytes were expected to be prevalent, some of the guilds did not include known endophytic roles. The patterns of assigned guilds also were quite variable between the various seeds.

Table 1 Statistical summary of number of reads and Molecular Operational Taxonomic Units (MOTUs) for the six sorghum cultivars investigated.

\begin{tabular}{llll}
\hline Cultivars & $\begin{array}{l}\text { Number of Reads before } \\
\text { QC }\end{array}$ & $\begin{array}{l}\text { Number of Reads after } \\
\text { QC }\end{array}$ & $\begin{array}{l}\text { Number of MOTUs } \\
\text { before taxon assignment }\end{array}$ \\
\hline NS5511 & 123618 & 94999 & 3397 \\
PAN8816 & 51892 & 27224 & 834 \\
PAN8420 & 55090 & 31686 & 1848 \\
PAN8625 & 78379 & 61298 & 2342 \\
PAN8906 & 63629 & 47383 & 2245 \\
PAN8706W & 49142 & 28741 & 3397 \\
\hline
\end{tabular}


Table 2 Comparative Percentage Abundance from Taxa plots of fungal in different taxonomic ranks in seeds of six cultivars of sorghum measured by Illumina Sequencing of the ITS2 Region.

\begin{tabular}{|c|c|c|c|c|c|c|c|}
\hline Division $^{\mathrm{a}}$ & NS5511 & PAN8816 & PAN8420 & PAN8625 & PAN8906 & PAN8706W & Average \\
\hline Ascomycota & 88.6 & 98.3 & 87.6 & 96.3 & 95.1 & 92.4 & 93.1 \\
\hline Basidiomycota & 0 & 0.4 & 0.1 & 0.3 & 0.3 & 0.2 & 0.2 \\
\hline Total percentage abundance & 88.6 & 98.7 & 87.6 & 96.6 & 95.4 & 92.6 & 93.3 \\
\hline \multicolumn{8}{|l|}{ Class } \\
\hline Dothideomycetes & 53.9 & 78.3 & 31.5 & 22.9 & 22.2 & 36.7 & 40.9 \\
\hline Eurotiomycetes & 0 & 0 & 0 & 0 & 0.1 & 0 & 0.0 \\
\hline$\underline{\text { Leotiomycetes }}$ & 0 & 0.1 & 0 & 1.0 & 0 & 0.2 & 0.2 \\
\hline Saccharomycetes & 0 & 0 & 0 & 0.1 & 0 & 0 & 0.0 \\
\hline Sordariomycetes & 2.6 & 0 & 0 & 0.1 & 0 & 0.1 & 0.5 \\
\hline Tremellomycetes & 0 & 0.4 & 0.1 & 0.1 & 0.2 & 0 & 0.1 \\
\hline$\overline{\text { Total percentage abundance }}$ & 56.5 & 78.8 & 31.6 & 24.1 & 22.5 & 37.1 & 41.8 \\
\hline \multicolumn{8}{|l|}{ Orders } \\
\hline Capnodiales & 1.5 & 0.2 & 0.9 & 0.3 & 0.1 & 0.2 & 0.5 \\
\hline Dothideales & $\mathbf{0 . 0}$ & 71.4 & 0 & 0.2 & 0 & 0 & 11.9 \\
\hline Pleosporales & 45.5 & 6.5 & 28.3 & 22.5 & 22. & 32.6 & 26.2 \\
\hline Eurotiales & 0 & 0 & 0 & 0.0 & 0.1 & 0 & 0.0 \\
\hline$\overline{\text { Erysiphales }}$ & 0 & 0 & 0 & 1.0 & 0 & 0.2 & 0.2 \\
\hline Saccharomycetales & 0 & 0 & 0 & 0.1 & 0 & 0 & 0.0 \\
\hline Hypocreales & 2.6 & 0 & 0 & 0 & 0 & 0.1 & 0.5 \\
\hline Phyllachorales & $\mathbf{0}$ & 0 & 0 & 0 & 0 & 0.1 & 0.0 \\
\hline Filobasidiales & 0 & 0.4 & 0 & 0.1 & 0.1 & 0 & 0.1 \\
\hline Total percentage abundance & 49.6 & 78.6 & 29.3 & 24.1 & 22.5 & 33.3 & 39.6 \\
\hline \multicolumn{8}{|l|}{ Families } \\
\hline Incertae sedis & 22.1 & 0.5 & 7.6 & 0.1 & 0.6 & 11.1 & 7.0 \\
\hline Mycosphaerellaceae & 1.5 & 0.2 & 0.6 & 0.3 & 0.1 & 0.2 & 0.5 \\
\hline $\begin{array}{l}\text { Dothioraceae } \\
\end{array}$ & 0 & 53.0 & 0 & 0.1 & 0 & 0 & 8.9 \\
\hline Phaeosphaeriaceae & 0 & 0 & 0.1 & 0 & 0 & 0 & 0.0 \\
\hline Pleosporaceae & 14.4 & 5.9 & 17.3 & 22.4 & 21.2 & 17.1 & 16.4 \\
\hline Trichocomaceae & 0 & 0 & 0 & 0 & 0.1 & 0 & 0.0 \\
\hline$\overline{\text { Erysiphaceae }}$ & 0 & 0.1 & 0 & 1.0 & 0 & 0.2 & 0.2 \\
\hline Nectriaceae & 2.4 & 0 & 0 & 0 & 0 & 0.1 & 0.4 \\
\hline Phyllachoraceae & 0 & 0 & 0 & 0 & 0 & 0.1 & 0.0 \\
\hline Filobasidiaceae & 0 & 0.4 & 0 & 0.1 & 0.1 & 0 & 0.1 \\
\hline Total percentage abundance & 40.4 & 60.1 & 25.7 & 24.0 & 22.2 & 28.9 & 33.6 \\
\hline \multicolumn{8}{|l|}{ Genera } \\
\hline Toxicocladosporium & 0.0 & 0.0 & 0.4 & 0.0 & 0.0 & 0.0 & 0.1 \\
\hline Cladosporium & 1.4 & 0.2 & 0.5 & 0.3 & 0.1 & 0.2 & 0.5 \\
\hline Aureobasidium & 0.0 & 53.0 & 0.0 & 0.1 & 0.0 & 0.0 & 8.9 \\
\hline Phoma & 22.1 & 0.5 & 7.2 & 0.0 & 0.6 & 11.1 & 6.9 \\
\hline Ampelomyces & 0.0 & 0.0 & 0.1 & 0.0 & 0.0 & 0.0 & 0.0 \\
\hline Alternaria & 8.6 & 5.8 & 14.6 & 22.4 & 21.0 & 15.3 & 14.6 \\
\hline Epicoccum & 5.7 & 0.1 & 2.7 & 0.0 & 0.2 & 1.7 & 1.7 \\
\hline Aspergillus & 0.0 & 0.0 & 0.0 & 0.0 & 0.1 & 0.0 & 0.0 \\
\hline Erysiphe & 0.0 & 0.1 & 0.0 & 0.8 & 0.0 & 0.2 & 0.2 \\
\hline Kodamaea & 0 & 0.0 & 0.0 & 0.1 & 0.0 & 0.0 & 0.0 \\
\hline Fusarium & 2.4 & 0.0 & 0.0 & 0.0 & 0.0 & 0.0 & 0.4 \\
\hline Colletotrichum & 0.0 & 0.0 & 0.0 & 0.0 & 0.0 & 0.1 & 0.0 \\
\hline Cryptococcus & 0.0 & 0.4 & 0.0 & 0.1 & 0.1 & 0.0 & 0.1 \\
\hline Total percentage abundance & 40.2 & 60.0 & 25.6 & 23.7 & 22.1 & 28.8 & 33.4 \\
\hline
\end{tabular}

${ }^{\text {a }}$ Names are used as assigned by the UNITE database used in the pipeline. 




Figure 2 - Percentage relative abundance of fungi (up to genus level) in seeds of six sorghum cultivars at 99\% level of sequence similarity. 


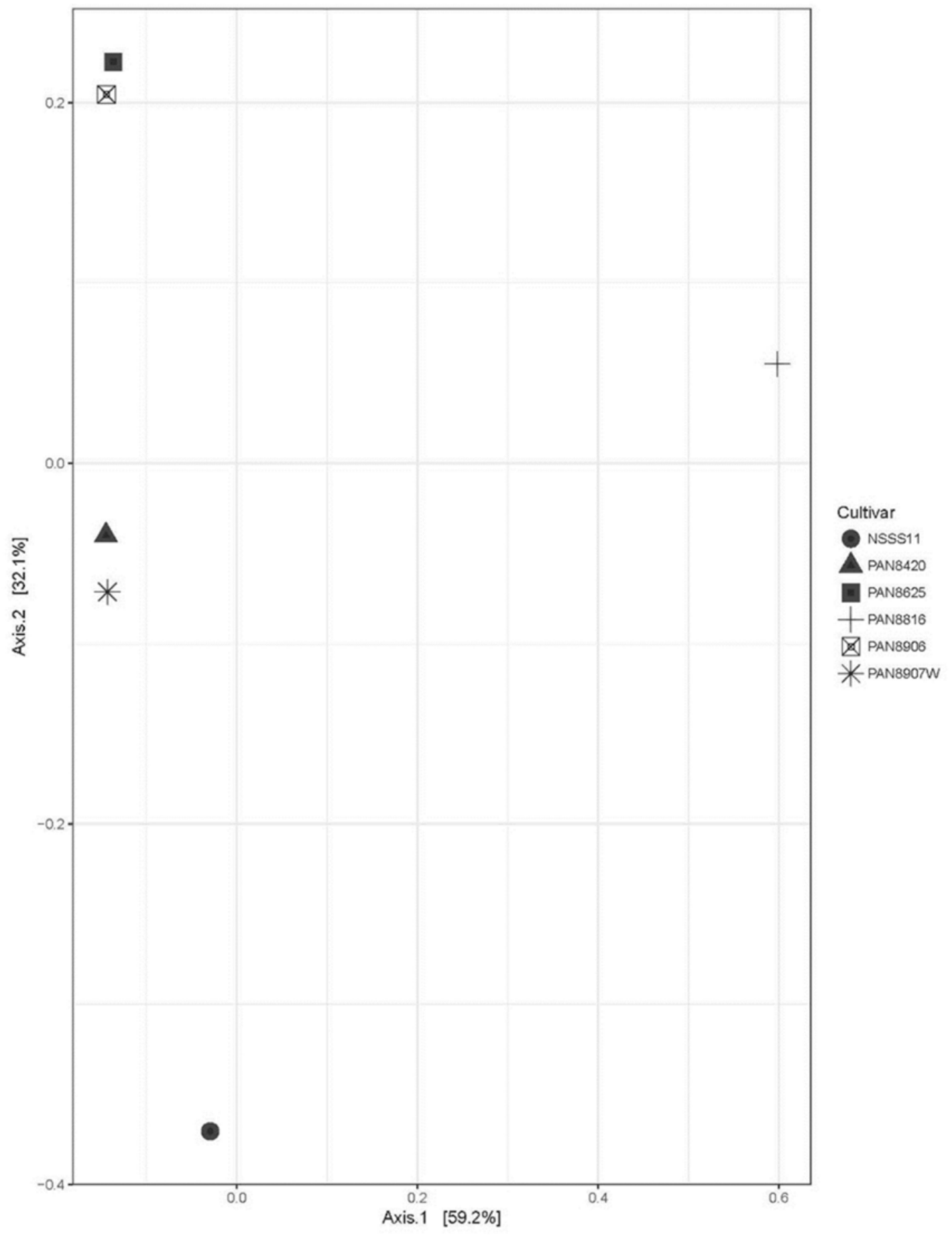

Figure 3 - Principal Coordinate Analysis of mycobiome in seeds of six sorghum cultivars obtained with Bray-curtis distances in R. The graph was based on MOTUs defined at a 99\% similarity cutoff.

\section{Phylogenetic analysis}

Phylogenetic analyses of Illumina reads yielded more precise placements for MOTUs than the automated hits. Reads were either placed in sections or species complexes for some genera, or names given to others were discounted. Putative species positions could also be assigned to some MOTUs. Phylogenetic analysis of the ITS2 region for Alternaria sequences placed MOTUs in the Alternata alternata complex (Bootstrap support 98\%), with MOTUs having a great deal of sequence variation (Fig. 5a). MOTUs of Fusarium were genetically diverse and grouped in the 
Fusarium incarnatum-equiseti species complex (bootstrap support 99\%), F. chlamydosporum species complex (bootstrap support 98\%), F. graminearum species complex (bootstrap support 98\%), Bisifusarium (bootstrap support 100\%) and possibly in the collapsed F. fujikuroi species complex (Fig. 5b). The phylogenetic tree for Colletotrichum (Fig. 5c) showed that a sequence read grouped in a clade containing C. truncatum, C. aciculare and C. jasminigenum (weakly supported based on bootstrap). Species could, unfortunately, not be distinguished with confidence for these genera.

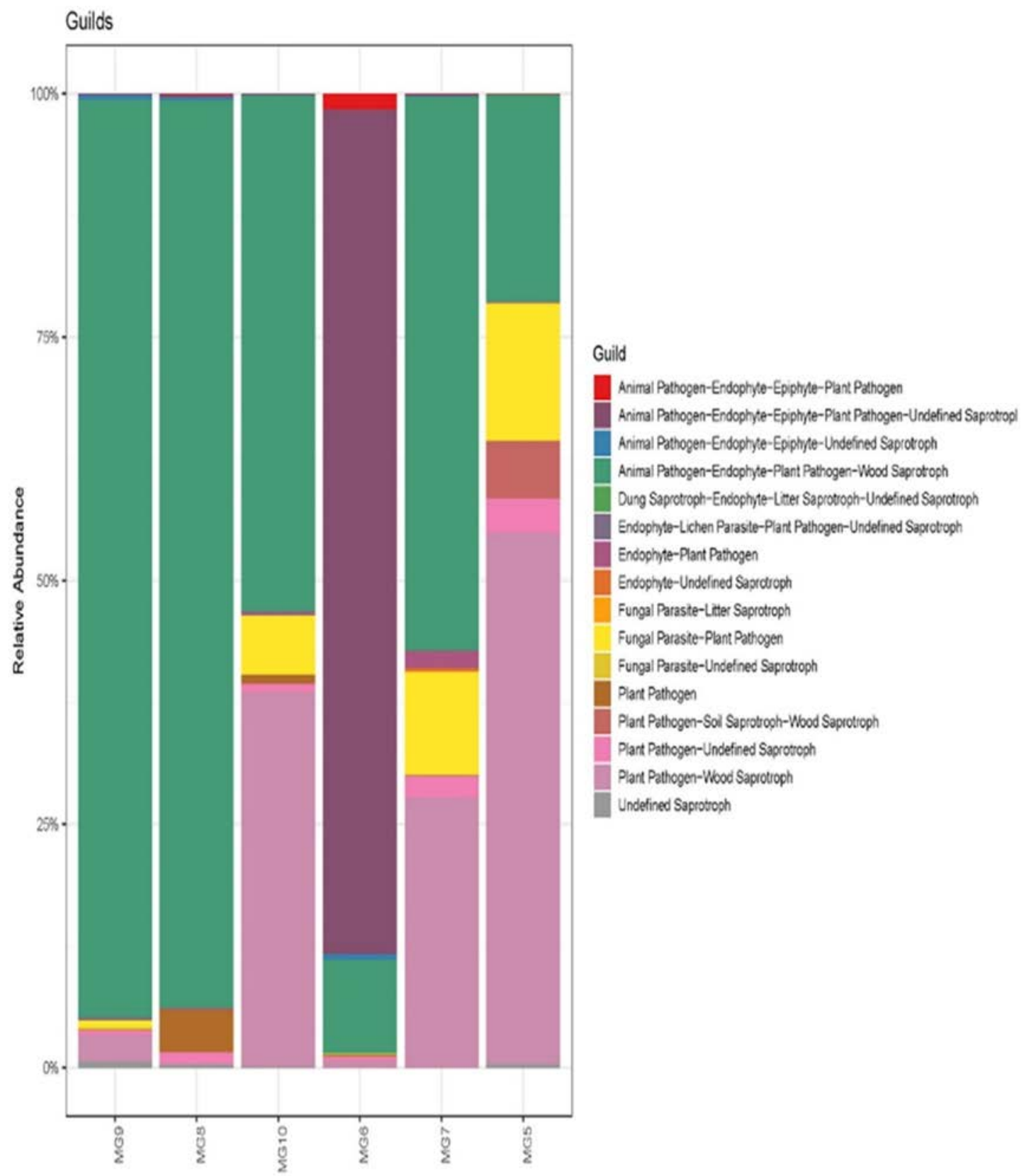

Figure 4 - Ecological guilds assigned with FUNGuild to prominent MOTUs that could be identified to genus level.

Three groups of Aureobasidium sequences formed, including A. namibae (bootstrap support 92\%), three different sequences grouping with $A$. melanogenum, and a possible unnamed species (Fig. 5d). Species sequences from GenBank showed (Fig. 6a) that MOTUs grouped with Cryptococcus luteolus (MG10 7046, bootstrap support 100\%), MG9 25372 grouped close to C. 
terrestris (bootstrap support 99\%), and MG7 5975 grouped in a clade consisting of C. flavescens and C. laurentii (bootstrap support 80\%). Three reads of Aspergillus grouped close to Aspergillus reticularus, Aspergillus penicillioides (bootstrap support 94\%) and Aspergillus restrictus, respectively (Fig. 6b). Three reads (MG33980, MG617262 and MG107179) identified as Erysiphe (Fig. 6c) grouped close to Erisyphe multappendicis (Bootstrap support 92\%) and E. berberidicola.

Unfortunately, the partial ITS region, and even the ITS region alone, had inadequate resolutions to distinguish between current genera in the Cladosporiaceae and Dydimellaceae, and MOTUs could thus not be assigned to an appropriate genus. More detailed multi-gene phylogenetic analyses will be required for these taxa. It is thus unclear if reads assigned as "Phoma" and "Epicoccum", or "Cladosporium" and "Toxicladosporium" truly belong to these genera. Although the particular dataset used for the Cochliobolus/Bipolaris group showed a majority of Bipolaris taxa grouping close to the read, the generic status of these genera were weakly supported and needs to be validated further. It is thus difficult to assign a proper genus to the sequences. However, the reads did group with sequences of Bipolaris victoriae, B. zeicola and B. sorokiniana, and close to sequences labelled as Cochliobolus lunatus and Curvularia lunata (Fig. 6d).

\section{Discussion}

We characterized the seed mycobiome of six cultivars of sorghum using Illumina sequencing of the ITS2 region. Rarefaction curves showed that more samples should be analysed for a better reflection of the true endophytic diversity. Besides this limitation, all seeds were found to contain fungi with complex ecological roles belonging to 41 MOTUs (99\% similarity cutoff). The most prominent family was the Pleosporaceae, represented mostly by the MOTUs assigned to the phytopathogen genus Alternaria. Other potentially detrimental fungi were also detected in the seed after phylogenetic analyses was conducted. This is in agreement with previous observations (Tesfaendrias et al. 2011, Beukes et al. 2017), suggesting that seeds are often infected by phytopathogenic fungi.

Alternaria and Aureobasidium species and those in the Didymellaceae (assigned by the pipeline to "Phoma" and "Epicoccum") dominated the fungal communities. However, Aureobasidium was only dominant in one cultivar. Taxa assigned to Fusarium, Colletotrichum, Aspergillus, Cryptococcus and Erisyphe, were also found but they were not as dominant and ubiquitous. Other important pathogens or problem groups, namely taxa linked to Cochliobolus and Cladosporiaceae, were also detected but in low numbers. These, and MOTUs of possible importance in the Didymellaceae and some in the Pleosporaceae, could not be satisfactorily assigned to an appropriate genera without the use of additional gene regions.

Additional phylogenetic analyses assisted greatly in more precise identification of MOTUs and yielded more information on the possible roles of the fungi in the seeds. Even if precise species identifications were not possible with ITS data in taxonomically extensive fungal groups, the MOTU identities could be narrowed down to some candidate species, or placed in sections or species complexes, as is the case for Alternaria and Fusarium. It also elucidated the occurrence of more than one MOTU within fungal genera or families.

Presence, absence or prominence of important groups or species can be revealed, which influence control measures or quarantine. In the case of Aspergillus, the three MOTUs could be closely assigned to species not really known to be important as mycotoxin producers (Sklenár et al. 2017), while important species such as A. fumigatus and A. flavus were not detected. Colletotrichum sublineolum that causes anthracnose of sorghum and represents one of the main constraints in sorghum production throughout the world (Basavaraju et al. 2009), was not detected. Instead the MOTU was identified as $C$. truncatum/C. aciculare/C. jasminigenum, none of which are important on sorghum, with $C$. truncatum an important pathogen on various other crops such as peppers (Damm et al. 2009). However, in some cases results can be misleading since the ITS sequence for certain species has not been produced. For instance, there is no ITS sequence in GenBank for Curvularia penisetti, which is known to be associated with disease symptoms of sorghum (Patil et al. 2008). 
A large number of taxa that could not be assigned to genus level were detected. This suggests that endophytic fungi are substantially understudied or underrepresented in the UNITE database, especially those from South Africa. Initiatives such as the Top50 search function in UNITE will be useful to refine the identities of these unknown sequences (Nilsson et al. 2016).

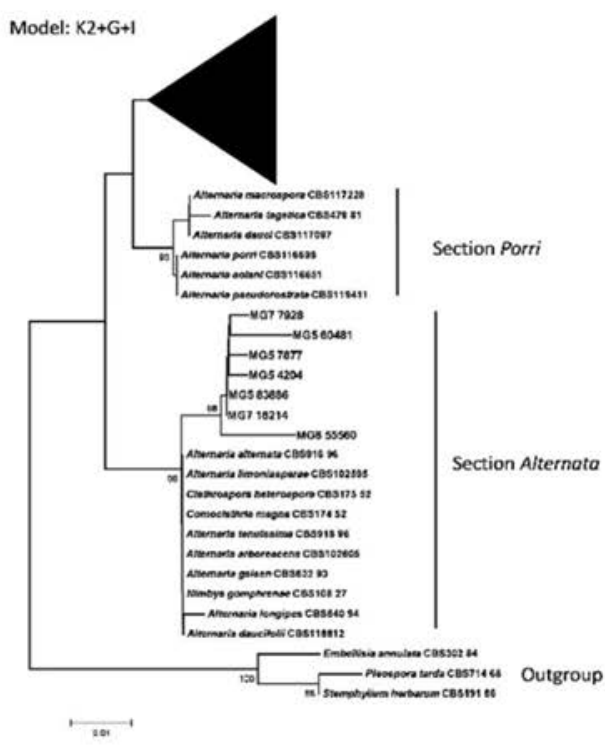

(a)

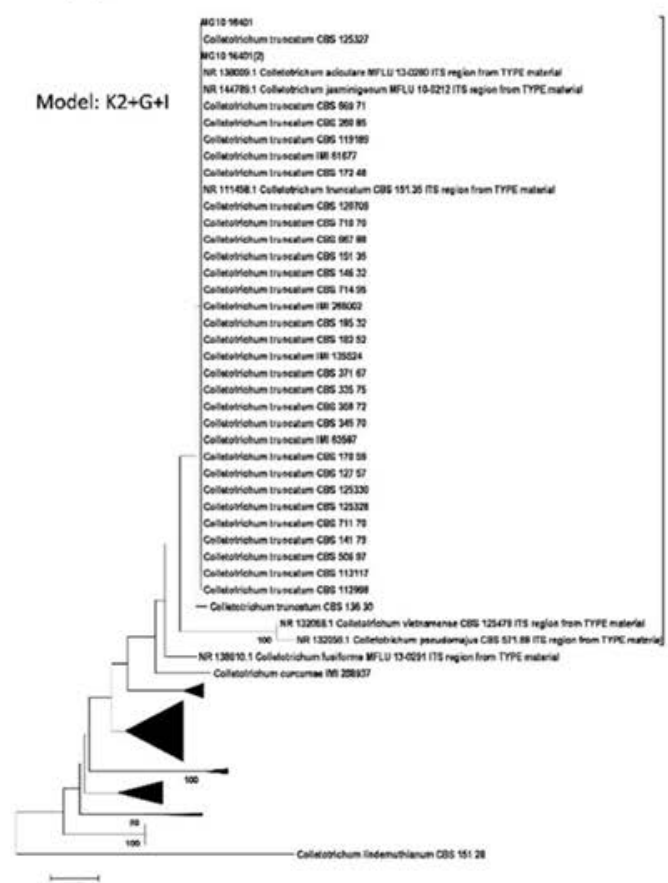

(c)

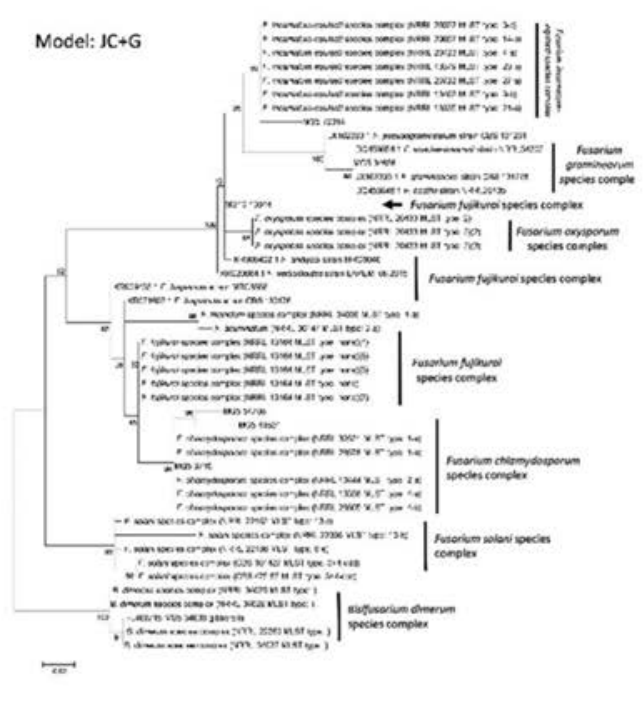

(b)



(d)

Figure 5 - Phylograms obtained from Maximum Likelihood analyses of the Internal Transcribed Spacer 2 region evolutionary model used indicated in the figure. Confidence levels $\geq 80 \%$ (1000 replicate bootstrap analysis) are indicated on the branches. Sequence reads obtained in this study are indicated with MG codes (a) Alternaria. (b) Fusarium. (c) Colletotrichum. (d) Aureobasidium. 


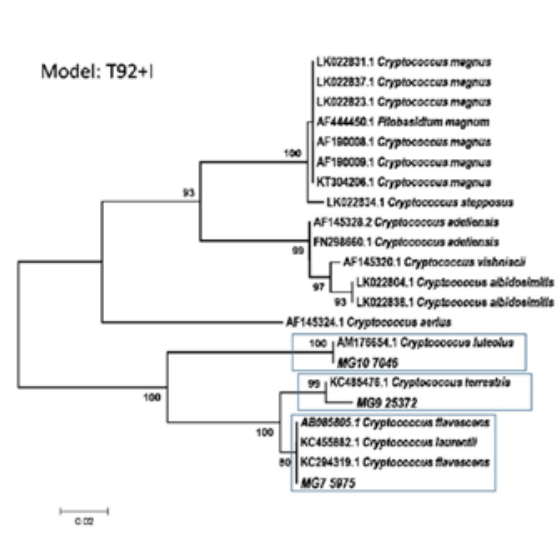

(a)

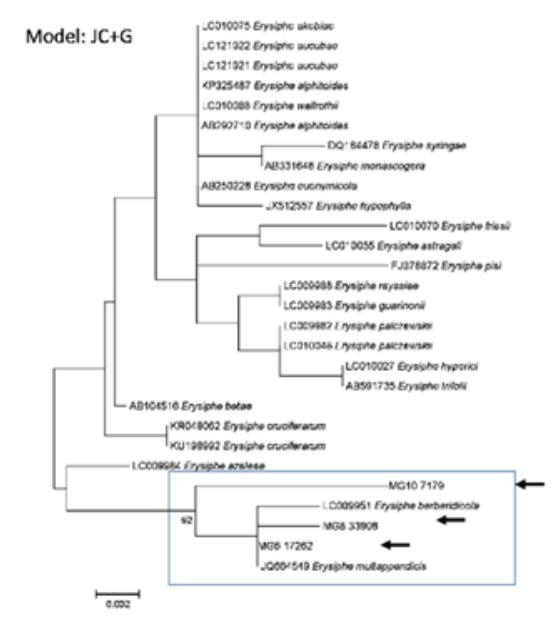

(c)

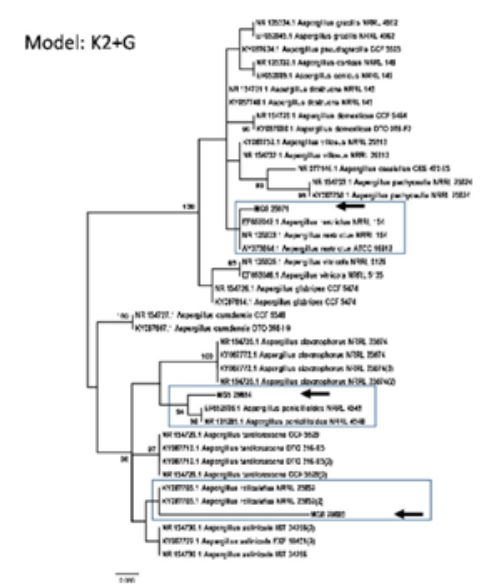

(b)

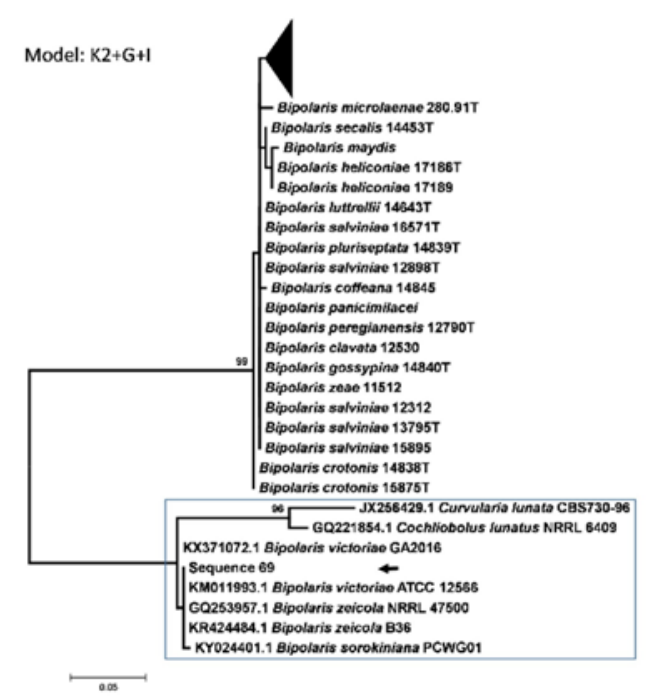

(d)

Figure 6 - Phylograms obtained from Maximum Likelihood analyses of the Internal Transcribed Spacer 2 region evolutionary model used indicated in the figure. Confidence levels $\geq 80 \%$ (1000 replicate bootstrap analysis) are indicated on the branches. Sequence reads obtained in this study are indicated with MG codes (a) Cryptococcus. (b) Aspergillus. (c) Erysiphe. (d) Cochliobolus.

In this study we have shown that with careful consideration and additional analyses more information on possible genus and even species identities can be obtained. This may yield meaningful ecological data and aids the detection of problematic fungi. Trends shown on order or family level can also be better explained. For instance, the Dothideales were mostly represented only by one genus, namely Aureobasidium, and the prominence of the Pleosporaceae across all cultivars were mostly due to the prominence of one genus, namely Alternaria. However, results showed that care should be taken when assigning generic and species names to MOTUs and should 
only be done in careful consideration to existing, often complex, taxonomies and responsible name assignments (Nilsson et al. 2011, Jeewon et al. 2018, Hongsanang et al 2018).

A major limitation to sorghum production is grain mold disease (Sharma et al. 2010), which is caused by species of Fusarium, Alternaria, and the Cochliobolus/Curvularia/Bipolaris complexes (Tarekegn et al. 2006, Tesfaendrias et al. 2011). Commonly isolated species are Fusarium thapsinum, Alternaria alternata and Curvularia lunata (Tarekegn et al. 2006, Tesfaendrias et al. 2011). Infection can significantly reduce grain yield and quality or contribute to deterioration during storage (Stack \& Pedersen 2003). Members of these fungi have been detected in the tested seeds, with especially Alternaria being omnipresent and in high proportions. In contrast, Fusarium and the Cochliobolus complex were detected sporadically across the tested cultivars and in low proportions. Although it is not known whether these fungi are viable in the seed, as amplicon sequencing can detect DNA from both viable and non-viable organisms (Louws et al. 1999, Tringe \& Ruben 2005), it nonetheless indicates the degree to which seeds have been infected, most likely while being in the field (Stack \& Pedersen 2003).

PCoA analyses showed that the fungal assemblages of some seedlots were similar in composition. However, the origin of the seeds used for isolations is unknown, and they could originate from different localities in South Africa. Significant variations in sorghum fungi have been found across locations, and among sorghum lines at a particular location (Thakur et al. 2003). Without such knowledge it will thus be difficult to ascertain if this similarly reflects geographic origin, if it could be a cultivar effect or an artefact of sampling.

A relatively low number of MOTUs were shared between the seeds from all six cultivars. These include a number of unassigned taxa, but especially Alternaria MOTUs. Species in this pathogenic and mycotoxin-producing genus is known to have a cosmopolitan occurrence and wide host range, including seed substrates (Bottalico \& Logrieco 1998, Woudenberg et al. 2013). The fact that Alternaria is so prominent in samples from these six cultivars, which include seeds with unknown origins, indicates that this genus can readily infect sorghum seeds.

Seed-borne fungal pathogens and mycotoxin producers play a significant, yield-limiting role in sorghum production world-wide, and could cause severe health problems in humans and livestock after consumption. Despite the limitations in species level identification, the use of NGS and phylogenies applied in the present study has provided a more precise dissection of the diversity and composition of the seed transmitted mycobiome in sorghum. A further advantage of the approach is that it can be done for a high number of samples, which greatly reduces cost (Adey et al. 2010). Previously extensive and exhaustive culturing would have been needed to reveal the diversity from the same sample size. Although care should be taken that DNA of killed organisms on the seed surface could maybe influence results, such information can contribute to better understanding of fungal communities in seeds of sorghum cultivars. It may also lead to better management practices, and aid studies investigating possible differences in the seed mycobiome of cultivars, areas and even other crops.

\section{Acknowledgements}

We are thankful to University of the Free State, Bloemfontein, South Africa for providing a postdoctoral scholarship to the first author. Research funding was provided by the Agricultural Research Council Collaborative Consortium to Broaden the Food Base. Profs Neal McLaren and Gert Marais (University of the Free State) provided seed samples and advice during the writing of the manuscript, respectively. Drs Vincent Robert and Ewald Groenewald (Johanna Westerdijk Institute, The Netherlands) provided assistance in obtaining DNA sequence datasets for the phylogenetic analyses.

\section{References}

Abdulsalaam S, Shenge KC. 2011 - Seed borne pathogens on farmer-saved sorghum (Sorghum bicolor L.) seeds. Journal of Stored Products and Postharvest Research 2, 24-28. 
Adey A, Morrison HG, Asan, Xun X, Kitzman JO et al. 2010 - Rapid, low-input, low-bias construction of shotgun fragment libraries by high-density in vitro transposition. Genome Biol. 11(12), R119

Adugna A. 2014 - Analysis of in situ diversity and population structure in Ethiopian cultivated Sorghum bicolor (L.) landraces using phenotypic traits and SSR markers. Springer plus 3, 212. Published online 2014 Apr 30. doi: 10.1186/2193-1801-3-212 PMCID: PMC4033718.

Baldani JI, Caruso L, Baldani VLD, Goi SR, Döbereiner J. 1997 - Recent advances in BNF with non-legume plants. Soil Biology and Biochemistry 29, 911-922.

Basavaraju P, Shetty NP, Shetty HS, de Neergaard E, Jørgensen HJL. 2009 - Infection biology and defence responses in sorghum against Colletotrichum sublineolum. Journal of Applied Microbiology 107, 404-415.

Bensch K, Braun U, Groenewald JZ, Crous PW. 2012 - The genus Cladosporium. Studies in Mycology 72, 1-401.

Beukes I, Rose JL, Shephard GS, Flett BV, Viljoen A. 2017 - Mycotoxigenic Fusarium species associated with grain crops in South Africa - A review. South African Journal of Science $113,1-12$.

Bottalico A, Logrieco A. 1998 - Toxigenic Alternaria species of economic importance. In: Sinha, K.K. and Bhatnagar, D. (Eds.) Mycotoxins in agriculture and food safety. Marcel Dekker, Inc, New York, USA, pp. 65-108.

Caporaso JG, Lauber CL, Walters WA, Berg-Lyons D et al. 2012 - Ultra-high-throughput microbial community analysis on the Illumina HiSeq and MiSeq platforms. International Society for Microbial Ecology Journal 6, 1621-1624.

Caporaso JG, Kuczynski J, Stombaugh J, Bittinger K et al. 2010 - QIIME allows analysis of highthroughput community sequencing data. Nature Methods 7, 335-336.

Chen Q, Jiang JR, Zhang GZ, Cai L, Crous PW. 2015 - Resolving the Phoma enigma. Studies in Mycology 82, 137-217.

Cook D, Beaulieu WT, Mott IW, Riet-Correa F et al. 2013 - Production of the alkaloid swainsonine by a fungal endosymbiont of the Ascomycete order Chaetothyriales in the host Ipomoea carnea. Journal of Agriculture and Food Chemistry 61, 3797-3803.

Dawson WAJM, Bateman GL. 2001 - Fungal communities on roots of wheat and barley and effects of seed treatments containing fluquinconazole applied to control take-all. Plant Pathology 50, 5-82.

Damm U, Woudenberg JHC, Cannon PF, Crous PW. 2009 - Colletotrichum species with curved conidia from herbaceous hosts. Fungal Diversity 39, 45-87.

Dicko MH, Gruppen H, Zouzouho OC, Traoré AS et al. 2006 - Effects of germination on amylases and phenolics related enzymes in fifty sorghum varieties grouped according to food-end use properties. Journal of the Science of Food and Agriculture 86, 953-963.

Edgar RC. 2010 - Search and clustering orders of magnitude faster than BLAST. Bionformatics 26, 2460-2461.

Frederiksen RA, Odvody G. 2000 - Compendium of Sorghum Diseases, 2nd ed. St. Paul, MN, APS Press.

Ferreira A, Quecine MC, Lacava PT, Oda S et al. 2008 - Diversity of endophytic bacteria from Eucalyptus species seeds and colonization of seedlings by Pantoea agglomerans. FEMS Microbiology Letters 287, 8-14.

Galperin M, Graf S, Kenigsbuch D. 2003 - Seed treatment prevents vertical transmission of Fusarium moniliforme, making a significant contribution to disease control. Phytoparasitica 31, 344-352.

González HH, Molto GA, Pacin A, Resnik SL, Zelaya MJ, Masana M. 2008 - Trichothecenes and mycoflora in wheat harvested in nine locations in Buenos Aires province, Argentina. Mycopathologia 165, 105-114.

Hussein HS, Brasel JM. 2001 - Toxicity, metabolism, and impact of mycotoxins on humans and animals. Toxicology 167, 101-134. 
Hodgson S, de Cates C, Hodgson J, Morley NJ et al. 2014 - Vertical transmission of fungal endophytes is widespread in forbs. Ecology and Evolution 4, 1199-1208.

Hongsanang S, Jeewon R, Purahong W, Thongbai B et al. 2018 - Can we use environmental DNA as holotypes? Fungal Diversity 92, 1-30.

Hugenholtz P, Goebel BM, Pace NR. 1998 - Impact of culture-independent studies on the emerging phylogenetic view of bacterial diversity. Journal of Bacteriology 180, 4765-4774.

Hyde KD, Soytong K. 2008 - The fungal endophyte dilemma. Fungal Diversity 33, 163-173.

Islam SMM, Masum MMI, Fakir MGA. 2009 - Prevalence of seed-borne fungi in sorghum of different locations of Bangladesh. Scientific Research and Essays 4, 175-179.

Jeewon R, Hyde KD. 2007 - Diversity and detection of Fungi from environmental samples: Traditional versus Molecular approaches. In (Eds A. Varma \& R, Oelmuller) Advanced Techniques in Soil Microbiology (pp 1-11). Soil Biology Series. Springer-Verlag Press.

Jeewon R, Yeung QSY, Wannasinghe DN, Rampadarath S et al. 2018 - Hidden mycota of pine needles: Molecular signatures from PCR-DGGE and Ribosomal DNA phylogenetic characterization of novel phylotypes. Scientific Reports https://doi.org/10.1038/s41598-01836573-z

Katoh K, Rozewicki J, Yamada KD. 2017 - MAFFT online service: multiple sequence alignment, interactive sequence choice and visualization. Briefings in Bioinformatics 1-7, https://doi.org/10.1093/bib/bbx108.

Kaga H, Mano H, Tanaka F, Watanabe A et al. 2009 - Rice seeds as sources of endophytic bacteria. Microbes and Environments 24, 154-162.

Kassim MY. 1985 - Seed-borne fungi of sorghum in Saudi Arabia, National Agricultural Research Centre, http://agris.fao.org/agris-search/search.do?recordID=PK8700352

Knief C, Delmotte N, Chaffron S, Stark M et al. 2012 - Metaproteogenomic analysis of microbial communities in the phyllosphere and rhizosphere of rice. International Society for Microbial Ecology Journal 6, 1378-1390.

Kõljalg U, Nilsson RH, Abarenkov K, Tedersoo L et al. 2013 - Towards a unified paradigm for sequence-based identification of Fungi. Molecular Ecology 22, 5271-5277.

Kuraku S, Zmasek CM, Nishimura O, Katoh K. 2013 - a Leaves facilitates on-demand exploration of metazoan gene family trees on MAFFT sequence alignment server with enhanced interactivity. Nucleic Acids Research 41, W22-W28.

Lakshmanan V, Selvaraj G, Bais HP. 2014 - Functional soil microbiome: belowground solutions to an aboveground problem. Plant Physiology 166, 689-700.

Leslie JF, Summerell BA. 2006 - The Fusarium laboratory manual. Blackwell Publishing, Ames, Iowa.

Li PD, Jeewon R, Aruna B, YeLi H et al. 2019 - Metabarcoding reveals differences in fungal communities between unflooded versus tidal flat soil in coastal saline ecosystem. Science of the Total Environment. https://doi.org/10.1016/j.scitotenv.2019.06.473

Louws FJ, Rademaker JLW, de Bruijn FJ. 1999 - The three D's of PCR based genomic analysis of phytobacteria: Diversity, detection and disease diagnosis. Diversity, Detection, and Disease Diagnosis. Annual Review of Phytopathology 37, 81-125.

Manamgoda DS, Cai L, McKenzie EHC, Crous PW et al. 2012- A phylogenetic and taxonomic reevaluation of the Bipolaris - Cochliobolus - Curvularia Complex. Fungal Diversity 56, 131144.

Mancini V, Murolo S, Romanazzi G. 2016 - Diagnostic methods for detecting fungal pathogens on vegetable seeds. Plant Pathology 65, 691-703.

McMurdie PJ, Holmes S. 2013 - "phyloseq: An R package for reproducible interactive analysis and graphics of microbiome census data.” PLoS ONE 8, e61217. http://dx.plos.org/10.1371/journal.pone.0061217.

Mendes R, Kruijt M, de Bruijn I, Dekkers E et al. 2011 - Deciphering the rhizosphere microbiome for disease-suppressive bacteria. Science 332, 1097-1100. 
Nguyen NH, Song Z, Bates ST, Branco S et al. 2016 - FUNGuild: an open annotation tool for parsing fungal community datasets by ecological guild. Fungal Ecology 20, 241-248.

Nilsson R, Tedersoo L, Lindahl BD, Kjoller R et al. 2011 - Towards standardization of the description and publication of next generation sequencing datasets of fungal communities. New Phytologist 191, 314-318.

Nilsson RH, Ryberg M, Abarenkov K, Sjökvist E, Kristiansson E. 2009 - The ITS region as a target for characterization of fungal communities using emerging sequencing technologies. FEMS Microbiology Letters 296, 97-101.

Nilsson RH, Ryberg M, Kristiansson E, Abarenkov K et al. 2006 - Taxonomic reliability of DNA sequences in public sequence databases: a fungal perspective. PLoS ONE, 10.1371/journal.pone.0000059.

Nilsson RH, Wurzbacher C, Bahram M, Coimbra VRM et al. 2016 - Top 50 most wanted fungi. MycoKeys 12, 29-40.

Oldrup W, Mclain-Romero J, Padilla A, Moya A et al. 2010 - Localization of endophytic Undifilum fungi in locoweed seed and influence of environmental parameters on a locoweed in vitro culture system. Botany 88, 512-521.

Oliver EJ, Thrall PH, Burdon JJ, Ash JE. 2001 - Vertical disease transmission in the CakileAlternaria host-pathogen interaction. Australian Journal of Botany 49, 561-569.

Op De Beeck MO, Lievens B, Busschaert P, Declerck S et al. 2014 - Comparison and validation of some ITS primer pairs useful for fungal metabarcoding studies. PLoS One 9, e97629. doi:10.1371/journal.pone.0097629

Panchal VH, Dhale DA. 2011 - Isolation of seed borne fungi of sorghum (Sorghum vulgare pers.) Journal of Phytopathology 3, 45-48.

Patil PJ, Padule DN, Suryawanshi JS, Pinjari SS. 2008 - Fungi associated with moldy sorghum (Sorghum bicolor (L) Moench) cv. CSH-9 in Western Maharashtra. International Journal of Plant Protection 1, 84-8711.

Patil VB, Chavan NS, Deshmukh K. 2014 - Study of Genetic Diversity among Sorghum bicolor (L.) Cultivars. International Research Journal of Management Science and Technology 5, 257-262.

Parsa S, García-Lemos AM, Castillo K, Ortiz V et al. 2016 - Fungal endophytes in germinated seeds of the common bean, Phaseolus vulgaris. Fungal Biology 120, 783-790.

Paulson JN, Stine OC, Bravo HC, Pop M. 2013 - Robust methods for differential abundance analysis in marker gene surveys. Nature Methods 10, 1200-1202.

Peay KG, Kennedy PG, Talbot JM. 2016 - Dimensions of biodiversity in the Earth mycobiome. Nature Reviews Microbiology 14, 434-447. doi: 10.1038/nrmicro.2016.59

Ralphs MH, Cook D, Gardner DR, Grum DS. 2011 - Transmission of the locoweed endophyte to the next generation of plants. Fungal Ecology 4, 251-255.

Rooney LW, Waniska RD. 2004 - Crop Utilization and Marketing: Food and Nutritional Quality of Sorghum and Millet. Report Project TAM226. Department Texas A\&M University College Station Texas, USA. pp. 77843-2474.

Sharma R, Deshpande SP, Senthilvel S, Rao VP et al. 2010 - SSR allelic diversity in relation to morphological traits and resistance to grain mould in sorghum. Crop and Pasture Science 61, 230-240.

Schmieder R, Edwards R. 2011 - Quality control and pre-processing of metagenomic datasets. Bioinformatics 27, 863-864.

Schoch CL, Robbertse B, Robert V, Vu D et al. 2014 - Finding needles in haystacks: linking scientific names, reference specimens and molecular data for Fungi Database 1, bau061, https://doi.org/10.1093/database/bau061

Sklenáŕ F, Jurjević Z, Zalar P, Frisvad JC et al. 2017 - Data from: Phylogeny of xerophilic aspergilli (subgenus Aspergillus) and taxonomic revision of section Restricti, Dryad, Dataset, https://doi.org/10.5061/dryad.3t423 
Sowley ENK, Dewey FM, Shaw MW. 2010 - Persistent, symptomless, systemic, and seed-borne infection of lettuce by Botrytis cinerea. European Journal of Plant Pathology 126, 61-71.

Spenceley J, Butler G, Nicholas A, Simpfendorfer S, Holland J, Kniepp J et al. 2005 - Grain Sorghum. NSW Department of Primary Industries.

Stack JP, Pedersen JF. 2003 - Expression of susceptibility to Fusarium head blight and grain mold in $A_{1}$ and $A_{2}$ cytoplasms of Sorghum bicolor. Plant Disease 87, 172-176.

Stokholm MS, Wulff EG, Zida EP, Thio IG et al. 2016 - DNA barcoding and isolation of vertically transmitted ascomycetes in sorghum from Burkina Faso: Epicoccum sorghinum is dominant in seedlings and appears as a common root pathogen. Microbiological Research 191, 38-50.

Tan YP, Madrid H, Crous PW, Shivas RG. 2014 - Johnalcornia gen. et. comb. nov., and nine new combinations in Curvularia based on molecular phylogenetic analysis. Australasian Plant Pathology 43, 589-60.

Tarekegn G, McLaren NW, Swart WJ. 2006 - Effects of weather variables on grain mould of sorghum in South Africa. Plant Pathology 55, 238-245. doi:10.1111/j.1365-3059.2005.01333.x

Tesfaendrias MT, McLaren NW, Swart WJ. 2011 - Grain mold fungi and their effect on sorghum grain quality. South African Journal of Plant and Soil 28, 172-180.

Thakur RP, Rao VP, Navi SS, Garud TB et al. 2013 - Sorghum Grain Mold Variability in Fungal Complex. Plant Pathology and Microbiology Publications

https://lib.dr.iastate.edu/plantpath_pubs/21 “The Plant List: Sorghum”. Royal Botanic Gardens Kew and Missouri Botanic Garden. Retrieved 28 February 2017.

Tringe SG, Rubin EM. 2005 - Metagenomics: DNA sequencing of environmental samples. Nature Reviews Genetics 6, 805-814.

Wani ZA, Ashraf N, Mohiuddin T, Riyaz-Ul-Hassan S. 2015 - Plant-endophyte symbiosis, an ecological perspective. Applied Microbiology and Biotechnology 99, 2955-2965.

Wiese MV 1984 - Compendium of wheat diseases. 3rd Ed. Am. Phytopathol. Soc., p. 106.

Woudenberg C, Groenewald JZ, Binder M, Crous PW. 2013 - Alternaria redefined. Studies in Mycology 75, 171-21.

Yago JI, Roh J, Bae S, Yoon Y et al. 2011 - The Effect of Seed-borne Mycoflora from Sorghum and Foxtail Millet Seeds on Germination and Disease Transmission. Mycobiology 39, 206218.

Zain ME. 2011 - Impact of Mycotoxins on humans and animals. Journal of Saudi Chemical Society 15, 29-144.

Zhang J, Kobert K, Flouri T, Stamatakis A. 2014 - PEAR: a fast and accurate Illumina paired-end read merger. Bioinformatics 30, 614-620.

Zida PE, Sérémé P, Leth V, Sankara P et al. 2008b - Importance of seed borne fungi of sorghum and pearl millet in Burkina Faso and their control using plant extracts. Pakistan Journal of Biological Sciences 11, 321-331. 